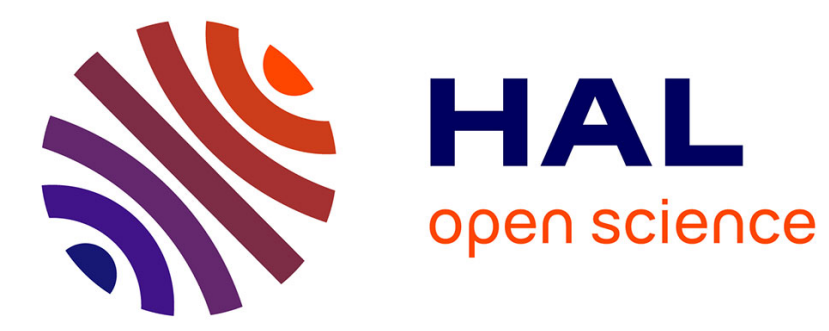

\title{
Dynamic Behaviour of a Flexible Yacht Sail Plan
}

Benoit Augier, Patrick Bot, Frédéric Hauville, Mathieu Durand

\section{To cite this version:}

Benoit Augier, Patrick Bot, Frédéric Hauville, Mathieu Durand. Dynamic Behaviour of a Flexible Yacht Sail Plan. Ocean Engineering, 2013, 66, pp.32-43. 10.1016/j.oceaneng.2013.03.017 . hal01071543

\section{HAL Id: hal-01071543 \\ https://hal.science/hal-01071543}

Submitted on 6 Oct 2014

HAL is a multi-disciplinary open access archive for the deposit and dissemination of scientific research documents, whether they are published or not. The documents may come from teaching and research institutions in France or abroad, or from public or private research centers.
L'archive ouverte pluridisciplinaire HAL, est destinée au dépôt et à la diffusion de documents scientifiques de niveau recherche, publiés ou non, émanant des établissements d'enseignement et de recherche français ou étrangers, des laboratoires publics ou privés. 


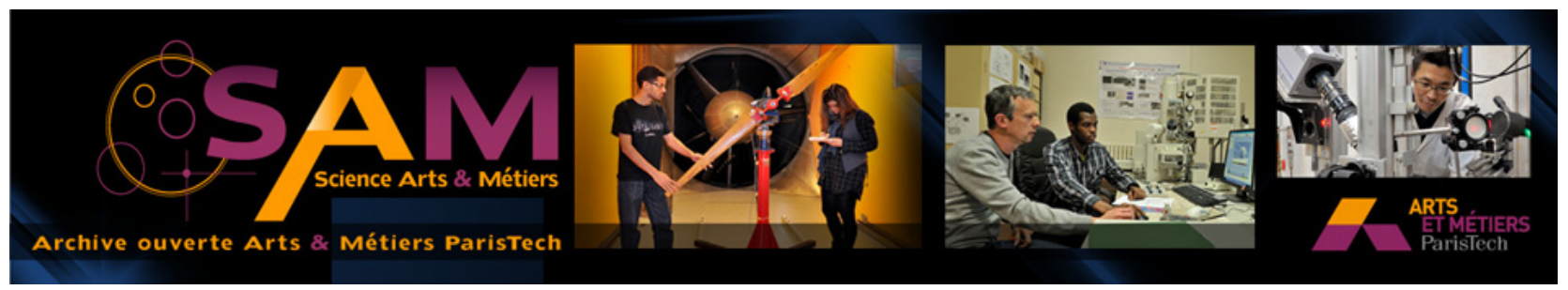

Science Arts \& Métiers (SAM)

is an open access repository that collects the work of Arts et Métiers ParisTech researchers and makes it freely available over the web where possible.

This is an author-deposited version published in: http://sam.ensam.eu

Handle ID: .http://hdl.handle.net/10985/8689

\section{To cite this version :}

Benoit AUGIER, Patrick BOT, Frédéric HAUVILLE, Mathieu DURAND - Dynamic Behaviour of a Flexible Yacht Sail Plan - Ocean Engineering - Vol. 66, p.32-43 - 2013 


\title{
Dynamic Behaviour of a Flexible Yacht Sail Plan
}

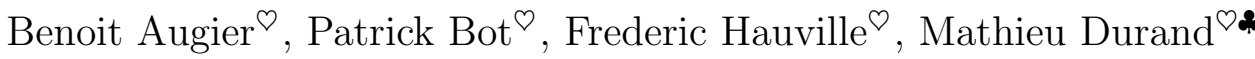 \\ ${ }^{\circ}$ Naval Academy Research Institute - IRENAV CC600, 29240 BREST Cedex 9, France \\ * K-Epsilon Company, 1300 route des Cretes - B.P 25506905 Sophia Antipolis Cedex, \\ France
}

\begin{abstract}
A numerical investigation of the dynamic Fluid Structure Interaction (FSI) of a yacht sail plan submitted to harmonic pitching is presented to address both issues of aerodynamic unsteadiness and structural deformation. The FSI model - Vortex Lattice Method fluid model and Finite Element structure model - has been validated with full-scale measurements. It is shown that the dynamic behaviour of a sail plan subject to yacht motion clearly deviates from the quasi-steady theory. The aerodynamic forces presented as a function of the instantaneous apparent wind angle show hysteresis loops, suggesting that some energy is exchanged by the system. The area included in the hysteresis loop increases with the motion reduced frequency and amplitude. Comparison of rigid versus soft structures shows that FSI increases the energy exchanged by the system and that the oscillations of aerodynamic forces are underestimated when the structure deformation is not considered. Dynamic loads in the fore and aft rigging wires are dominated by structural and inertial effects. This FSI model and the obtained
\end{abstract}

Email address: patrick.bot@ecole-navale.fr Tel:+33 298233986 (Patrick Bot $\left.^{8}\right)$ 
results may be useful firstly for yacht design, and also in the field of auxiliary wind assisted ship propulsion, or to investigate other marine soft structures.

Keywords:

Fluid Structure Interaction, Dynamic behaviour, Yacht Sails, Soft

Membrane, Unsteady, Numerical/experimental comparison 


\section{Nomenclature}

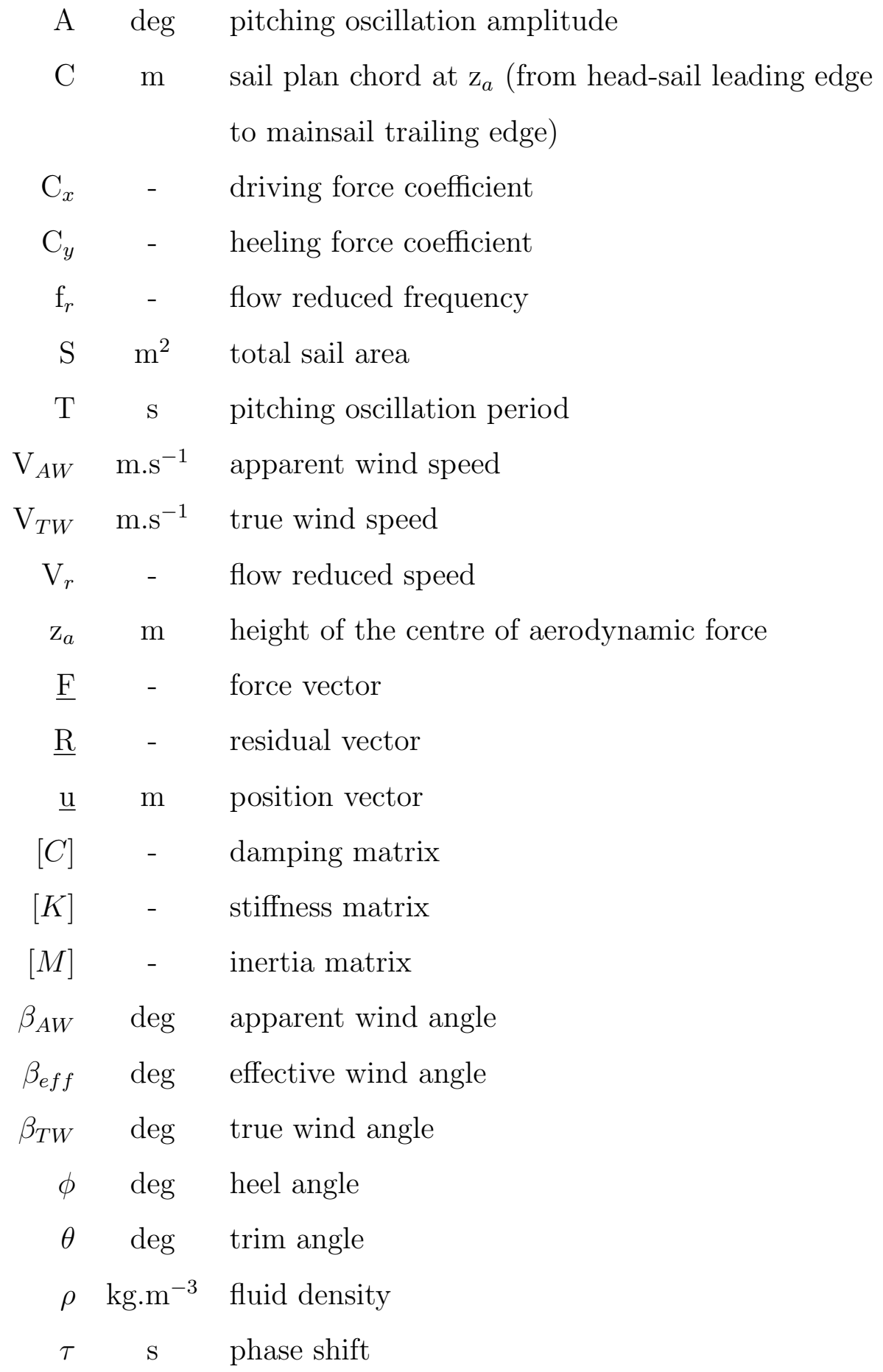




\section{Introduction}

It is now well-known that deformations actively or passively endured by aerodynamic and hydrodynamic lifting bodies have a significant effect on the flow dynamics and the performance of the system. A huge amount of work has been devoted to insects' and birds' flight, (?) or to fishes swim (?, ?), for example for applications in Micro Air Vehicles (MAV) and more generally in the bio-mimetic field (for a review, see ?). From this abundant literature, it has been shown that the dynamic behaviour of the flow and the structural deformation must be considered to better understand the mechanisms involved in lifting and propulsive performances (?). For example in the field of insect flight, ? have underlined the necessity to consider the dynamic phenomena to properly estimate aerodynamic coefficients.

Fluid structure interaction is also of interest for some compliant marine structures, such as wave attenuation systems (?) or in the field of Ocean Thermal Energy Conversion (OTEC) where soft ducts made of a membrane and stiffeners may be interesting for the cold water pipe $(?, ?)$. To reduce fuel consumption and emissions in maritime transport, wind assisted propulsion is more and more considered for ships $(?, ?, ?)$.

When analysing the behaviour of yacht sails, an important difficulty comes from the Fluid Structure Interaction (FSI) of the air flow and the sails and rig (?, ?, ?). Yacht sails are soft structures whose shapes change according to the aerodynamic loading. The resulting modified shape affects the air flow and thus, the aerodynamic loading applied to the structure. This 
Fluid Structure Interaction is strong and non-linear, because sails are soft and light membranes which experience large displacements and accelerations, even for small stresses. As a consequence, the actual sail's shape while sailing — the so-called flying shape — is different from the design shape defined by the sail maker and is generally not known. Recently, several authors have focused on the Fluid Structure Interaction (FSI) problem to address the issue of the impact of the structural deformation on the flow and hence the aerodynamic forces generated $(?, ?)$.

Another challenging task in modelling racing yachts is to consider the yacht behaviour in a realistic environment $(?, ?, ?, ?)$. Traditional Velocity Prediction Programs (VPPs) used by yacht designers consider a static equilibrium between hydrodynamic and aerodynamic forces. Hence, the force models classically used are estimated in a steady state. However, in realistic sailing conditions, the flow around the sails is most often largely unsteady because of wind variations, actions of the crew and more importantly because of yacht motion due to waves. To account for this dynamic behaviour, several Dynamic Velocity Prediction Programs (DVPPs) have been developed, e.g. by ?, ?, ?, ? which need models of dynamic aerodynamic and hydrodynamic forces. While the dynamic effects on hydrodynamic forces have been largely studied, the unsteady aerodynamic behaviour of the sails has received much less attention. ? first developed an unsteady aeroelastic model in potential flow dedicated to flexible membranes but neglected the inertia. In a quasi-static approach, a first step is to add the velocity induced by the yacht's motion to the steady apparent wind to build an instantaneous 
apparent wind (see ?, ?) and to consider the aerodynamic forces corresponding to this instantaneous apparent wind using force models obtained in the steady state. In a recent study, ? developed an analytical model to predict the unsteady aerodynamics of interacting yacht sails in $2 \mathrm{D}$ potential flow and performed $2 \mathrm{D}$ wind tunnel oscillation tests with a motion range typical of a 90-foot (26m) racing yacht (International America's Cup Class 33). Recently, ?, ?, and ? studied the aerodynamics of model-scale rigid sails in a wind tunnel, and showed that a pitching motion has a strong and non-trivial effect on aerodynamic forces. They showed that the relationship between instantaneous forces and apparent wind deviates — phase shifts, hysteresis from the equivalent relationship obtained in a steady state, which one could have thought to apply in a quasi-static approach. They also investigated soft sails in the same conditions to highlight the effects of the structural deformation (?).

To better understand the aeroelastic behaviour, a numerical investigation is achieved with a simple harmonic motion to analyse the dynamic phenomena in a well-controlled situation. This paper addresses both issues of the effects of unsteadiness and structural deformation on a yacht sail plan with typical parameters of a 28 -foot $(8 \mathrm{~m}$, J80 class) cruiser-racer in moderate sea. An unsteady FSI model has been developed and validated with experiments in real sailing conditions (?, ?, ?). Calculations are made on a J80 class yacht numerical model with her standard rigging and sails designed by the sail maker DeltaVoiles. The dynamic results are compared with the quasi-steady assumption and the dynamic force coefficients are also compared with the 
experimental results obtained by ? for a rigid sail plan of a 48-foot (14.6m) cruiser-racer model. The FSI model is presented in section 2, and the experimental validation is presented in section 3. The methodology of the dynamic investigation is given in section 4 . The core of the paper (section 5) presents and analyses the simulation results regarding variation of force coefficients and loads in the rig due to pitching. In the last section, some conclusions of this study are given, with ideas for future work.

\section{Numerical model}

To numerically investigate aero-elastic problems which can be found with sails, the company K-Epsilon and the Naval Academy Research Institute have developed the unsteady fluid-structure model ARAVANTI made by coupling the inviscid flow solver AVANTI with the structural solver ARA. The ARAVANTI code is able to model a complete sail boat rig in order to predict forces, tensile and shape of sails according to the loading in dynamic conditions. The numerical models and coupling are briefly described below. For more details, the reader is referred to ? for the fluid solver AVANTI and to ? and ? for the structural solver ARA and the FSI coupling method.

\subsection{The inviscid fluid solver: AVANTI}

Flow modelling is based on the Vortex Lattice Method (VLM). This method is suitable for external flows where vorticity exists only in the boundary layers on the lifting surface and its wake. In the lifting surface model, the vorticity is represented by a non-planar doublet distribution along the 
lifting surface and the wake formed by the vortex shedding at the trailing edge is represented by a vortex sheet. This method is basically made up of two parts: a lifting body problem and a wake problem. These two problems are coupled by means of a kind of Kutta condition that has been derived from the kinematic and dynamic conditions along the separation lines. Usually, these lines are reduced to the trailing edges although more complicated situations have sometimes been considered. Except when writing this Kutta condition, the flow is assumed to be inviscid. The lifting problem is solved by means of a boundary integral method: the surface of the body is represented using panels of rectangular shape which are used to satisfy the potential slip condition. Specifically, a doublet strength is associated with each panel, and the strength of the doublet is adjusted by imposing that the normal velocity component at the surface of the body must vanish at control points. The aerodynamic force is computed with the doublet strength and local fluid velocity thanks to the doublet/vorticity equivalence introduced by ? (see also ?). The wake is modelled by means of the particles method itself developed by ? and then ?. According to this method, the vorticity distribution within the wake is described by means of virtual particles carrying vortices. The motion of particles is computed in a Lagrangian framework. The vorticity on each particle has to satisfy the Helmholtz equation. Dissipation of the wake is modelled by damping the particles' intensity in time - empirically adjusted, see ? - and neighbour particles of small intensity are merged. In practice, there are very few particles downstream a distance of four chord lengths from the trailing edge. 
For the incoming flow, the true wind is defined with the velocity at $10 \mathrm{~m}$ height and an atmospheric wind gradient is considered. Boat speed and motion are then considered to determine the apparent wind. This fluid model has been largely used and validated (?). As the fluid is supposed to be inviscid, the validity of the model is obviously limited to mostly attached flows, as it is the case for a sailing yacht on a close hauled course, where the sails' curvature and incidence are moderate. The viscous drag is not considered in the simulations.

\subsection{The structural software: $A R A$}

The structural model is a finite element model composed of beams (spars and battens), cables (wires and running rigging) and membranes (sails). The sail model is based on CST (Constant Strain Triangles) membrane model elements extended in 3 dimensions. Despite its simplicity, this choice has proven to give a good ratio of accuracy to computing power. The assumptions imposed inside this element are constant stresses, constant strains and uniform stiffness of the material. Non-linearities coming from the geometry and compression are taken into account. The non-linear finite element formulation based on the virtual work equation links the variation of forces to the vari-

ation of displacement. The Newmark-Bossak Interaction scheme (temporal discretisation) is based on a prediction-correction iterative method.

$$
\left(\underline{F}_{\text {inertial }}+\underline{F}_{\text {damping }}+\underline{F}_{\text {stiffness }}\right)+\underline{F}_{\text {external }}=\underline{R}
$$


Deriving these as a function of position, speed and acceleration results in a Newton-type scheme:

$$
[M] \underline{u}+[C] \underline{\dot{u}}+[K] \underline{u}=\underline{R}
$$

The Newmark scheme puts position, speed and acceleration in the following relation:

$$
\begin{aligned}
& {[K *] \underline{u}=\underline{R}} \\
& {[K *]=[M] \frac{1}{\xi \Delta t^{2}}+[C] \frac{\gamma}{\xi \Delta t}+[K]}
\end{aligned}
$$

Where $[\mathrm{M}]$ is the inertia matrix (mass and added mass), $[\mathrm{C}]$ is the damping matrix and $[\mathrm{K}]$ is the stiffness matrix. In the stress-strain relationship of the sail fabric, an anisotropic composite material is considered and the properties of several layers may be superimposed in the matrix $[\mathrm{K}]$ (films and strings for example).

The sail structure and panelling are imported from the sail designer software Sailpack which was used to make the sails, and the structural mesh is built according to the sail design. Mechanical properties of every component of the structure have been measured experimentally. 


\subsection{AVANTI/ARA coupling}

The effects of the interaction are translated into a coupling of the kinematic equation (continuity of the normal component of the velocity at the interface between fluid and structure geometrical domains) and dynamic equations (continuity of the normal component of the external force, pressure forces, on the contact surface of the sail with the fluid). An implicit iterative algorithm (see Figure 1) is used to coordinate the data exchanges between the fluid and structure solvers and to obtain a stable coupling. Two different meshes are used to satisfy the quality criteria of fluid mesh on one side and structural mesh on the other side. The deformation from the structural computation is introduced into the fluid mesh. Then, new forces from the fluid computation are interpolated in the structural code by a consistent method. In a previous study, much attention was devoted to validation of this FSI model with respect to full-scale experiments (?). A summary of the validation results is presented below.

\section{Experimental validation}

Numerical and experimental comparisons with the model ARAVANTI are based on measurements at full scale on an instrumented 28-foot yacht (J80 class, 8m). The time-resolved sails' flying shape, loads in the rig, yacht's motion and apparent wind have been measured in both sailing conditions of flat sea and moderate head waves. The comparisons are limited to upwind sailing conditions, as the flow model validity is limited to mostly attached flows. At first, the computed sail flying shape and loads in the rig were compared with 
the measurements in a steady state corresponding to flat sea. The predicted flying shape is in very good agreement with the measured one, as shown on Figure 2. Comparison of the computed and experimentally-measured parameters of the aerodynamic profiles - namely camber, draft, twist angle - shows a mean relative error of $2.5 \%$ and a maximum error of $6 \%$ in the worst case. The loads in the rig are also well predicted with less than $8 \%$ discrepancy for side stays and backstay, and $10 \%$ for the forestay (see Figure 3). More detailed description of the experimental system and methods and the quantitative comparison are given in ?, ? and ?.

For the dynamic regime, a yacht sailing upwind in a short swell with a constant true wind of $7 \mathrm{~m} . \mathrm{s}^{-1}(14 \mathrm{kts})$ is considered. The apparent wind variations are assumed to come only from the boat's motion. Recorded attitudes, from the motion sensors, are implemented as inputs in the simulation. Time series of some experimental and calculated loads are represented for a $20 \mathrm{~s}$ recording in Figure 4. The simulation resolves the dynamic behaviour of the loads consistently with the experimental measurements. The mean load value is slightly overestimated in the backstay and underestimated in the forestay, but the oscillations are reproduced well. The normalised intercorrelation function between measured and computed time series shows a maximum value higher than 0.8 with a phase shift lower than 0.1s. For more details on the model validation with full-scale experiments, the reader is referred to ?.

The code has shown its ability to simulate the rig's response to yacht 
motion forcing, and to correctly estimate the loads. The small observed discrepancies were mainly attributed to difficulties to determine precisely the environmental conditions and some inaccuracies in the mechanical properties of the structural elements. Thereby, ARAVANTI is a reliable tool to study the dynamic behaviour of a sail plan subject to pitching motion.

\section{Simulation Procedure}

The yacht motion in waves induces unsteady effects in the sails' aerodynamics. In this paper we will study separately one degree of freedom, by applying simple harmonic pitching. The reference frame and the coordinate system attached to the yacht are illustrated in Figure 5.

\subsection{Reference steady case}

First, the reference steady case is computed with the following parameters: true wind speed at $10 \mathrm{~m}$ height $\mathrm{V}_{T W}=6.7 \mathrm{~m} . \mathrm{s}^{-1}$ (a logarithmic vertical wind profile is imposed with a roughness length of $0.2 \mathrm{~mm}(?))$, true wind angle $\beta_{T W}=40^{\circ}$, boat speed $\mathrm{V}_{B S}=2.6 \mathrm{~m} . \mathrm{s}^{-1}$, heel angle $\phi=20^{\circ}$ and trim angle $\theta=0^{\circ}$. This first computation yields the converged steady flow, the rig and sails' flying shape, and enables the steady state aerodynamic forces and centre of effort to be determined. This converged steady state is used as the initial condition for the computations with pitching forcing. The height $\mathrm{z}_{a}$ of the centre of aerodynamic forces is used to define the flow characteristic quantities: apparent wind speed $\mathrm{V}_{A W}$, apparent wind angle $\beta_{A W}$ and sail plan chord $\mathrm{C}$ defined as the distance from the head-sail leading edge and the mainsail trailing edge at $\mathrm{z}_{a}$. Corrections of the apparent wind angle $\beta_{A W}$ due 
to constant heel $\phi$ (first introduced by ?) and trim $\theta$ are considered through the use of the effective apparent wind angle $\beta_{\text {eff }}$ (see ? for heel effect, and ? for pitch effect):

$$
\beta_{e f f}=\tan ^{-1}\left(\frac{\tan \beta_{A W}}{\cos \theta} \cos \phi\right)
$$

\subsection{Harmonic pitching}

The unsteady computations consist of a 20s run, with forced harmonic pitching being imposed on the rig, characterised by the oscillation amplitude $\mathrm{A}$ and period $\mathrm{T}$ (equation 6), other parameters being constant and equal to those of the reference state.

$$
\theta(t)=A \cos \left(\frac{2 \pi}{T} t\right)
$$

To avoid discontinuities in the accelerations, the beginning of motion is gradually imposed by applying a ramp which increases smoothly from 0 to 1 during the first 3s of imposed motion (see first period in Figure 7).

The investigation has been made with variables in the range $A=3$ to $6^{\circ}$, and $\mathrm{T}=1.5$ to $6 \mathrm{~s}$, corresponding to the typical environmental conditions encountered, as shown in the experiment of ?. The unsteady character of a flow is characterized by a dimensionless parameter defined by the ratio of the motion period $\mathrm{T}$ to the fluid advection time along the total sail plan chord $\mathrm{C}$. Similarly to the closely related literature $(?, ?)$, this parameter is called the flow reduced velocity $\mathrm{V}_{r}$ (or the inverse: the reduced frequency $\mathrm{f}_{r}$ ) defined by: 


$$
V_{r}=\frac{V_{A W} T}{C}=f_{r}^{-1}
$$

The case $\mathrm{V}_{r} \gg 1\left(\mathrm{f}_{r} \ll 1\right)$ corresponds to quasi-steady aerodynamic conditions. The pitching period values investigated correspond to a reduced velocity $\mathrm{V}_{r}$ from 2 to 8.5 (reduced frequency $\mathrm{f}_{r}$ from 0.12 to 0.47 ), which positions this numerical study in a similar dynamic range to the experiments of ? where $\mathrm{V}_{r}$ was from 2.3 to 56 (reduced frequency $\mathrm{f}_{r}$ from 0.02 to 0.43 ) corresponding to typical conditions encountered by a 48 -foot yacht $(14.6 \mathrm{~m})$. The computed cases are summarised in Table 1.

When the yacht is subjected to pitching motion, the apparent wind is periodically modified as the rotation adds a new component of apparent wind which varies with height. Following the analysis of ?, the apparent wind and pitch-induced velocity are considered at the centre of aerodynamic force height $\mathrm{z}_{a}$. This centre of effort is actually moving due to pitch oscillation, but variations are small enough to be ignored, and the reference height computed in the steady state is used. This yields time dependent apparent wind speed and angle, given by:

$$
\begin{aligned}
V_{A W}(t)= & \left(\left(V_{T W} \sin \beta_{T W}\right)^{2}\right. \\
& \left.+\left(V_{T W} \cos \beta_{T W}+V_{B S}+z_{a} \dot{\theta}(t)\right)^{2}\right)^{\frac{1}{2}} \\
\beta_{A W}(t)= & \sin ^{-1}\left(\frac{V_{T W} \sin \beta_{T W}}{V_{A W}(t)}\right)
\end{aligned}
$$

And hence the time-dependent effective wind angle: 


$$
\beta_{\text {eff }}(t)=\tan ^{-1}\left(\frac{\tan \beta_{A W}(t)}{\cos \theta(t)} \cos \phi\right)
$$

Figure 6 illustrates the dynamic vector composition for pitching velocities $\dot{\theta}=\dot{\theta}_{\text {max }}, 0$ and $\dot{\theta}_{\text {min }}$, and Figure 7 shows the resulting dynamic apparent wind velocity and angle computed with equations 8 and 9. As shown in Figure 7, the apparent wind angle variations are in phase opposition with the apparent wind speed.

\subsection{Heeling and driving force coefficients}

Aerodynamic forces are calculated by the code at the sail plan's centre of effort. Forces are written in the inertial reference frame, in order to get $\mathrm{F}_{x}$ and $\mathrm{F}_{y}$, the driving and the heeling forces. Driving and heeling force coefficients are obtained by the normalisation with the product of the instantaneous apparent dynamic pressure and the total sail area $\mathrm{S}$ :

$$
\begin{aligned}
C_{x}(t) & =\frac{F_{x}}{0.5 \rho V_{A W}^{2}(t) S} \\
C_{y}(t) & =\frac{F_{y}}{0.5 \rho V_{A W}^{2}(t) S}
\end{aligned}
$$

\section{Results}

From the unsteady FSI simulations, the aerodynamic forces and loads in the rig are determined and their dynamic evolution is analysed with respect to the instantaneous effective wind angle $\beta_{\text {eff }}(\mathrm{t})$ and pitching velocity $\dot{\theta}(t)$. Figure 8 shows an example of the computed results, with snapshots of 
the pressure distribution and the particles modelling the wake for a pitching oscillation amplitude $\mathrm{A}=5^{\circ}$ and a period $\mathrm{T}=3 \mathrm{~s}$. The unsteady behaviour is illustrated by the evolution of the pressure distribution on sails and the emitted particles' streaklines. The pressure field is presented in Figure 8.b and 8.d for the extreme values of apparent wind angle $\beta_{\text {eff }}(\mathrm{t})$, i.e. at trim angle $\theta=0^{\circ}$, increasing and decreasing. Notice also in Figure 8.a and 8.c the different pressure distributions observed for the same value of apparent wind angle $\beta_{\text {eff }}(\mathrm{t})$ but with opposite trim angles.

\subsection{Simulation with different reduced velocities $V_{r}$ and amplitudes $A$}

Calculations are made with a fixed pitching amplitude $\mathrm{A}=5^{\circ}$ and different periods, and with different amplitudes for a given period as illustrated in Table 1. Figure 9 shows the evolution of aerodynamic coefficients $\mathrm{C}_{x}(\mathrm{t})$ and $\mathrm{C}_{y}(\mathrm{t})$ with the instantaneous apparent wind angle $\beta_{\text {eff }}(\mathrm{t})$ for different values of the reduced velocity. From the initial condition corresponding to the reference steady state at $\beta_{\text {eff }}(0)=27.8^{\circ}$, the system oscillates under the forced pitching with a periodic behaviour as shown by the quasi-elliptic limit cycle drawn in the figure. The initial peak at the beginning of the run is due to imperfection in the restart by the dynamic computation scheme from the reference steady state. It is noticeable that the periodic behaviour is obtained after a short transient time of the order of the smoothing ramp applied on the motion initiation. The evolution of $\mathrm{C}_{x}$ and $\mathrm{C}_{y}$ with $\beta_{\text {eff }}$ in a steady case, obtained from steady computations for different $\beta_{\text {eff }}$ is also shown for comparison.

The periodic oscillation of the aerodynamic forces plotted as a func- 
Table 1: Reduced velocity $\mathrm{V}_{r}$, reduced frequency $\mathrm{f}_{r}$, phase delay $\tau$ and hysteresis loop area $\int_{T} C_{x} d \beta_{\text {eff }}$ for $\mathrm{C}_{x}$ and apparent wind angle $\beta_{\text {eff }}$ corresponding to the different tested pitch amplitudes $\mathrm{A}$ and periods $\mathrm{T}$.

\begin{tabular}{ccccccc}
\hline $\mathrm{T}$ & $\mathrm{A}$ & $\mathrm{V}_{r}$ & $\mathrm{f}_{r}$ & $\tau$ & $2 \pi \tau / \mathrm{T}$ & Loop area \\
\hline $\mathrm{s}$ & $\mathrm{deg}$ & - & - & $\mathrm{s}$ & $\mathrm{rad}$ & $\mathrm{deg}$ \\
1.5 & 5 & 2.13 & 0.47 & 0.1 & 0.42 & 2.12 \\
3 & 5 & 4.27 & 0.23 & 0.3 & 0.63 & 0.82 \\
5 & 5 & 7.11 & 0.14 & 0.6 & 0.75 & 0.42 \\
6 & 5 & 8.53 & 0.12 & 0.75 & 0.79 & 0.36 \\
\hline & & & & & & \\
\hline $\mathrm{T}$ & $\mathrm{A}$ & $\mathrm{V}_{r}$ & $\mathrm{f}_{r}$ & $\tau$ & $2 \pi \tau / \mathrm{T}$ & Loop area \\
\hline $\mathrm{s}$ & $\mathrm{deg}$ & - & - & $\mathrm{s}$ & $\mathrm{rad}$ & $\mathrm{deg}$ \\
5 & 3 & 7.11 & 0.14 & 0.6 & 0.75 & 0.15 \\
5 & 5 & 7.11 & 0.14 & 0.6 & 0.75 & 0.42 \\
5 & 6 & 7.11 & 0.14 & 0.6 & 0.75 & 0.61 \\
\hline
\end{tabular}


tion of the instantaneous effective wind angle is loop-shaped in the plane $\left(\mathrm{C}_{x, y}(\mathrm{t}), \beta_{\text {eff }}(\mathrm{t})\right)$. To better understand this behaviour and the origin of these loops, the phase shift $\tau$ between the signals was determined by crosscorrelation, and the aerodynamic coefficients $\mathrm{C}_{x, y}(\mathrm{t})$ were plotted versus the time-delayed wind angle $\beta_{\text {eff }}(\mathrm{t}+\tau)$. In these new plots, the area enclosed inside the loops is lower than in the former plots but does not vanish, and the loops do not collapse into a single line as would be the case for simply phase-shifted signals. Hence, this behaviour is the signature of an hysteresis phenomenon between the dynamic forces and the apparent wind angle. The phase delay and the hysteresis loop area are tabulated in Table 1. The phase delay increases with the reduced velocity (with the motion period) but is not affected by the oscillation amplitude.

As the reduced velocity decreases (shorter period), the area of the hysteresis loop increases importantly (Table 1), as the range of wind angles swept under pitching $\left(\Delta \beta_{e f f}\right)$ gets wider, and the slope of the hysteresis loop decreases.

Figure 10 shows the evolution of the aerodynamic coefficients $\mathrm{C}_{x}(\mathrm{t})$ and $\mathrm{C}_{y}(\mathrm{t})$ with the instantaneous effective wind angle $\beta_{\text {eff }}(\mathrm{t})$ for different values of the pitching amplitude. The area of the hysteresis loop is increased noticeably by the higher pitching amplitude. Although the reduced velocity is not changed, the amplitude has a strong effect on the unsteady character of the system as the rotation velocity is directly linked to the oscillation amplitude.

Tables 2 and 3 show the mean value and variation range for each variable 
Table 2: Mean value and variation range of force coefficients and $\beta_{\text {eff }}(\mathrm{t})$ for a pitching period variation

\begin{tabular}{lcccc}
\hline & A5T1.5 & A5T3 & A5T5 & A5T6 \\
\hline $\bar{C} \mathrm{x}$ & 0.38 & 0.36 & 0.36 & 0.36 \\
$\Delta \mathrm{Cx}$ & 0.39 & 0.21 & 0.16 & 0.15 \\
$\bar{C} \mathrm{y}$ & -1.21 & -1.16 & -1.14 & -1.14 \\
$\Delta \mathrm{Cy}$ & 0.93 & 0.46 & 0.37 & 0.35 \\
$\bar{\beta}_{e f f}\left({ }^{\circ}\right)$ & 28.84 & 28.03 & 27.81 & 27.79 \\
$\Delta \beta_{\text {eff }}\left({ }^{\circ}\right)$ & 16.22 & 7.77 & 4.62 & 3.84 \\
\hline
\end{tabular}

during one period of pitching. It may be noticed that the average effective wind angle varies with the pitching amplitude and period, even if the yacht is pitching around the same mean $\operatorname{trim} \theta=0^{\circ}$, because of the non-linearity of equation 9. The pitching period also has an influence on the hysteresis loop thickness and its centre, as illustrated in Table 2.

Increasing the pitch period moves the ellipse centre slightly towards lower values of $\beta_{\text {eff }}(\mathrm{t})$ and force coefficients (in absolute value). The pitch amplitude also has a great influence on the hysteresis loop's enclosed area. When the pitching amplitude is increased, the variation range of aerodynamic forces, the variation range of $\beta_{e f f}(\mathrm{t})$ and the mean value of $\beta_{\text {eff }}(\mathrm{t})$ increase, as tabulated in Table 3.

These results are very similar to the experimental results obtained by ?. 
Table 3: Mean value and variation range of force coefficients and $\beta_{\text {eff }}(\mathrm{t})$ for a pitching amplitude variation

\begin{tabular}{lccc}
\hline & $\mathrm{A} 3 \mathrm{~T} 5$ & $\mathrm{~A} 5 \mathrm{~T} 5$ & $\mathrm{~A} 6 \mathrm{~T} 5$ \\
\hline $\bar{C} \mathrm{x}$ & 0.36 & 0.36 & 0.36 \\
$\Delta \mathrm{Cx}$ & 0.13 & 0.16 & 0.19 \\
$\bar{C} \mathrm{y}$ & -1.14 & -1.14 & -1.14 \\
$\Delta \mathrm{Cy}$ & 0.30 & 0.37 & 0.40 \\
$\bar{\beta}_{\text {eff }}\left({ }^{\circ}\right)$ & 27.7 & 27.8 & 27.8 \\
$\Delta \beta_{\text {eff }}\left({ }^{\circ}\right)$ & 2.8 & 4.6 & 5.6 \\
\hline
\end{tabular}

Limit cycles show the same trends, centred on the steady state trend, with an increasing driving force and an increasing heeling force in absolute value $\left(\mathrm{C}_{y}<0\right)$ when $\beta_{\text {eff }}(\mathrm{t})$ is increasing.

\subsection{Effect of the structural deformation}

To assess the contribution of the structural behaviour on the system's response, results computed with the Fluid Structure Interaction (FSI) simulations presented above have been compared to fluid-only simulations considering a rigid structure.

The rigid structure (sails and rig) is the converged flying shape calculated from the FSI steady simulation (section 4.1), frozen into a fixed geometry for the unsteady fluid-only simulation with pitching forcing. Figure 11 shows the evolution of the calculated driving force coefficient $\mathrm{C}_{x}(\mathrm{t})$ for both FSI and rigid simulations. The enclosed area is smaller and the loop axis slope 
is slightly lower in the rigid structure case. Rigid structure calculations underestimate the hysteresis phenomenon and the stress variation. The same behaviour is observed for the side force coefficient $\mathrm{C}_{y}(\mathrm{t})$ (not shown here). Table 4 summarizes the mean values and the range of force coefficients and effective wind angle for several values of the pitching period. The variation range of the aerodynamic coefficients is underestimated by the fluid-only calculation, highlighting the importance of FSI simulation in the case of sails.

Table 4: Comparison between mean value and range of force coefficients and $\beta_{\text {eff }}(\mathrm{t})$ from Fluid only (rigid structure) and FSI (flexible structure) calculations

\begin{tabular}{lcc|cc}
\hline & $\begin{array}{c}\text { A5T1.5 } \\
\text { Rigid }\end{array}$ & A5T1.5 & A5T5 & A5T5 \\
& Rigid & FSI \\
\hline $\bar{C} \mathrm{x}$ & 0.38 & 0.38 & 0.37 & 0.36 \\
$\Delta \mathrm{Cx}$ & 0.31 & 0.39 & 0.13 & 0.16 \\
$\bar{C} \mathrm{y}$ & -1.22 & -1.21 & -1.16 & -1.14 \\
$\Delta \mathrm{Cy}$ & 0.76 & 0.93 & 0.32 & 0.37 \\
$\bar{\beta}_{\text {eff }}\left({ }^{\circ}\right)$ & 28.8 & 28.8 & 27.8 & 27.8 \\
$\Delta \beta_{\text {eff }}\left({ }^{\circ}\right)$ & 16.2 & 16.2 & 4.6 & 4.6 \\
\hline
\end{tabular}

\subsection{Loads in the rig}

The ARAVANTI code simulates the full rigging and gives access to the load experienced by the rig wires and sail vertices. Figure 12 shows the variations of load in the forestay, backstay and main sheet due to the pitching oscillation for various reduced velocities, tuned by the pitching period, as 
a function of effective wind angle $\beta_{\text {eff }}(\mathrm{t})$. A hysteresis loop is observed, as for the aerodynamic coefficients. The steady state trend is also shown for comparison, computed from steady simulations with different values of $\beta_{\text {eff }}$. The steady state trend is easily explained by the increase in loading of the rig with increase in the static angle of attack. In a quasi-static approach the same trend could be expected for the dynamic loads with $\beta_{\text {eff }}(\mathrm{t})$. However, the general trend shown by the main axis of the hysteresis loop is the opposite for the forestay and the main sheet: the load decreases for increasing $\beta_{\text {eff }}(\mathrm{t})$ which shows a phase opposition.

Actually, it is worth noticing that $\beta_{\text {eff }}(\mathrm{t})$ is itself in phase opposition to the pitching velocity $\dot{\theta}(\mathrm{t})$ (see Figure 7 ). In other words, the pitching velocity is maximal when $\beta_{e f f}(\mathrm{t})$ is minimal. Hence, the general trend of load in the forestay is an increase with increasing $\dot{\theta}(\mathrm{t})$ as shown on Figure 13. This observation suggests that the variations in the forestay load are governed by structural behaviour from the inertia of the rigging, rather than by the aerodynamic behaviour. Indeed, the motion is imposed on the hull by the effect of waves and when the yacht's bow is diving $(\dot{\theta}(\mathrm{t})>0)$, the forestay pulls the mast forward and the load increases. The opposite holds for the backstay, which explains the general trend observed in Figure 13: the backstay load increases with the negative of the pitching velocity $(-\dot{\theta}(\mathrm{t})$ : stern diving). The forces of inertia from the mast were estimated from the mast moment of inertia and angular acceleration, and projected along the forestay and the backstay. The resulting amplitude of inertial loads is the same order of magnitude as the load variations obtained from the FSI simulation for the 
forestay and the backstay. It may be concluded that the structural effect on the forestay and backstay loads is predominant in pitching motion. The influence of pitching velocity dominates the influence of the angle of attack.

The main sheet's loop axis slope has the same trend as that of the forestay, whereas the main sheet pulls the mast backwards as the backstay does. The load does not increase with $\beta_{\text {eff }}(\mathrm{t})$, but increases with pitching velocity $\dot{\theta}(\mathrm{t})$. A possible explanation may be that load variations in the main sheet are governed by the apparent wind speed $\mathrm{V}_{A W}(\mathrm{t})$. Variations of the apparent wind speed are due to pitching, so are in phase opposition with $\beta_{\text {eff }}(\mathrm{t})$. A maximum $\dot{\theta}(\mathrm{t})>0$ - and minimum $\dot{\theta}(\mathrm{t})<0$ - corresponds to a maximum — and minimum — of $\mathrm{V}_{A W}(\mathrm{t})$. The amplitude of inertial forces from the boom is one order of magnitude lower than the variations in main sheet load. Therefore, the boom inertia is not predominant in the main sheet load variations, and the effects of the whole rig inertia and apparent wind speed $\mathrm{V}_{A W}(\mathrm{t})$ may play a significant role.

\subsection{Loads in the rig measured in full-scale experiments}

The full-scale experiment described in section 3 enabled the loads in the rig to be measured. Figure 14 presents the experimental load variations versus the pitching velocity $\dot{\theta}(\mathrm{t})$ recorded at sea with the instrumented boat. The pitching period is $1.3 \mathrm{~s}$ (one period is shown) and the amplitude is around $2^{\circ}$. Even when the pitching is perturbed by the general boat motion in these real conditions (more complex than a pure harmonic pitching only), a hysteresis loop can be observed. The loop axis slopes for the forestay, backstay 
and main sheet confirm the trends observed in the simulation results, which supports the analysis put forth in the previous section. The enclosed area is smaller in the experimental set because the pitching amplitude is smaller than in the simulation.

\section{Conclusions}

The unsteady fluid structure interaction of the sails and rig of a 28-foot (8m) yacht under harmonic pitching motion has been investigated in order to highlight both contributions of the dynamic behaviour and the fluid structure interaction on a sail plan in realistic conditions. The ARAVANTI model is based on an implicit unsteady coupling between a vortex lattice fluid model and a finite element structural model, and has been validated with full-scale experiments in upwind real conditions (?). The contribution of pitching to the apparent wind has been analysed and the time-dependent apparent wind speed and angle were derived, in the framework of the effective wind angle (?) and the sail plan centre of effort velocity induced by pitching (?). Similar to the experimental results of ? obtained in a wind tunnel on the rigid sail plan model of a 48 -foot $(14.6 \mathrm{~m})$ yacht, the aerodynamic coefficients plotted against the instantaneous apparent wind angle show an hysteresis loop, which indicates that unsteady conditions lead to aerodynamic

equivalent damping and stiffening effects. Further simulations and analysis are underway to interpret this phenomenon in terms of energy exchanged by the aeroelastic system.

These results confirm that the dynamic behaviour of a sail plan subjected to yacht motion deviates from quasi-steady theory. Oscillations of the aero- 
dynamic forces show phase shifts and hysteresis loops which increase with the reduced frequency and amplitude of the motion. These conclusions differ from the results of ? who concluded to small unsteady lift amplitudes for the sails of a 90-foot (26m) International America's Cup Class yacht. Besides differences in the models, the higher variations shown here in the case of a 28foot $(8 \mathrm{~m})$ cruiser-racer in a moderate sea are mainly due to a higher forcing amplitude. The pitching motion induces an apparent wind velocity relative amplitude up to $30 \%$, compared to less than $7 \%$ in ?, and a wind-normal motion of the sails at the centre of effort height up to $10 \%$ of the total chord length at the same height, compared to less than $1 \%$ in ?.

Thanks to simulations with both rigid and flexible structures (sails and rig), the particular effect of the fluid structure interaction has been highlighted. Interestingly, the aerodynamic force amplitudes are greater in the case of the flexible structure considered here than for a rigid structure. For further work, it would be interesting to address this issue for different structure stiffness characteristics. Indeed, the dynamic FSI model may be used to study the effect of different tensions in the rig for various dynamic sailing conditions, which may prove to be very useful for rig design and rig tuning purposes. The simulation tool developed and the results of this work can be used by rig and sail designers to estimate the dynamic loads in the structure. The implications towards performance prediction and performance enhancement of yachts are not straightforward and a thorough analysis with an expert designer would be of great interest. 
As the fluid model is an inviscid VLM, the flow is assumed to be attached over the whole sail. However, there may be some non-negligible flow separation when soft sails are submitted to a pitching motion, as suggested by ?. This issue needs more investigation, and further developments are in progress to couple the structural model ARA with a RANSE solver.

The load oscillations in the rig under forced pitching have been analysed. A similar hysteresis loop has been found but the general trend for the forestay and backstay is related better to the pitching velocity than to the dynamic apparent wind. This suggests that the dynamic tensions in the rig are dominated by the effects of structural dynamics and rig inertia, compared to the aerodynamic effects. Understanding the behaviour of the load in the main sheet is less intuitive and requires more investigation. Both structural and aerodynamic behaviours may play significant roles.

This study opens up a large area for further work to better understand the FSI dynamics of yacht sails and rigs. In particular, more simulations and experimental work are needed to investigate the relative contributions of aerodynamics and structural dynamics in more detail. Furthermore, it would be interesting to explore a wider range of forced oscillation periods and amplitudes, as well as other excitations such as roll and yaw motion.

This work has shown the importance of accounting for the Fluid Structure Interaction and dynamic behaviour of a soft structure in an oscillatory flow in general. The model developed and the outcomes of this work may be useful 
for ship auxiliary wind-assisted propulsion and to investigate other marine soft structures.

\section{Acknowledgements}

The authors wish to thank Prof. Fossati of Politecnico di Milano for valuable discussions. His pioneering work on the subject strongly inspired the present study and analysis. The authors are grateful to the K-Epsilon company for continuous collaboration. This work was supported by the French Naval Academy. 


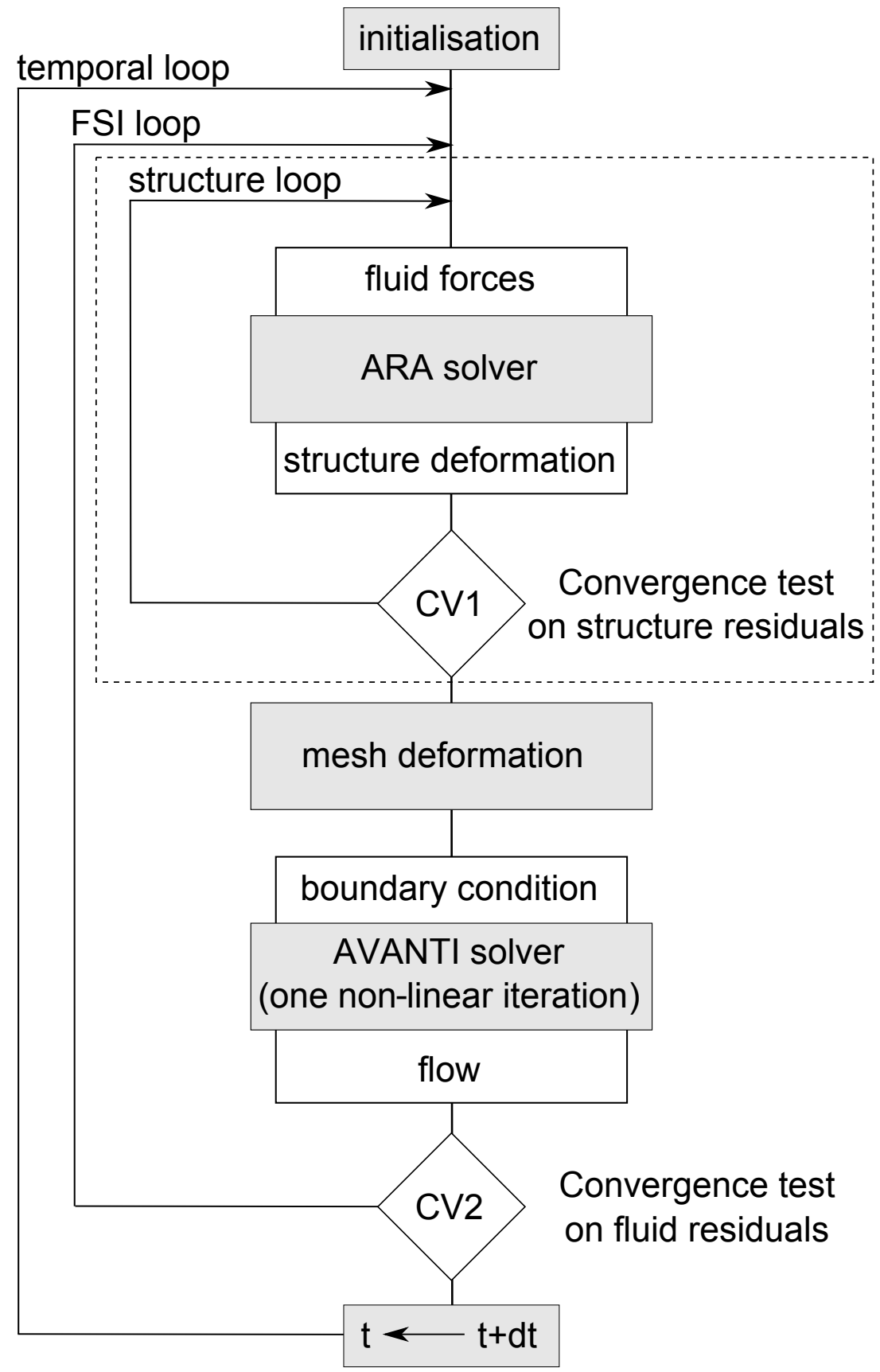

Figure 1: Implicit FSI coupling diagram 


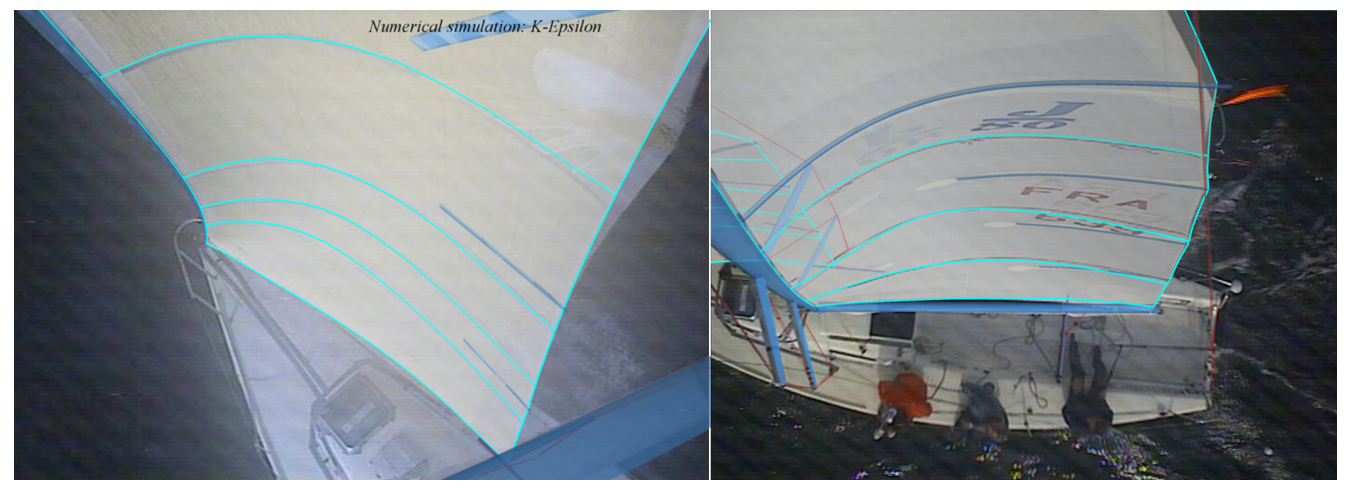

Figure 2: Superposition of the flying shape of the experimental sails and the numerical result on a yacht sailing upwind in a steady state. The picture and grey visualisation stripes show the measured flying shape; the blue thick lines show the computed position of the beams in the model (mast, boom, spreaders, battens); the light blue lines show the computed sail outline and the visualisation stripes. 


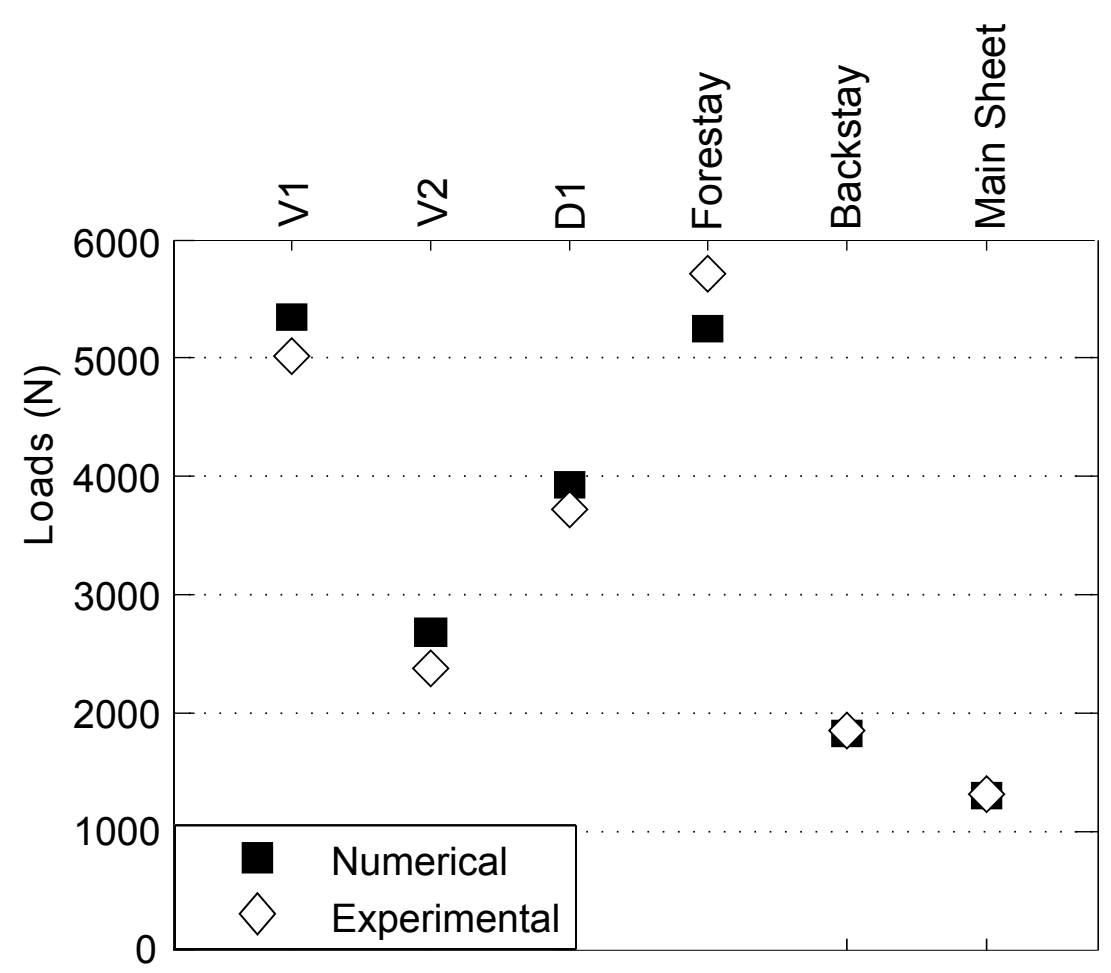

Figure 3: Experimental and numerical comparison on loads at steady state. Comparison is shown for the fore, aft and three windward side stays holding the mast, and for the mainsail sheet. V1 is the outer and longer side stay running from the mast top down to the yacht's deck; V2 is the intermediate side stay running from two thirds of the mast height down to the yacht's deck; D1 is the inner and shorter side stay running from one third of the mast height down to the yacht's deck. 


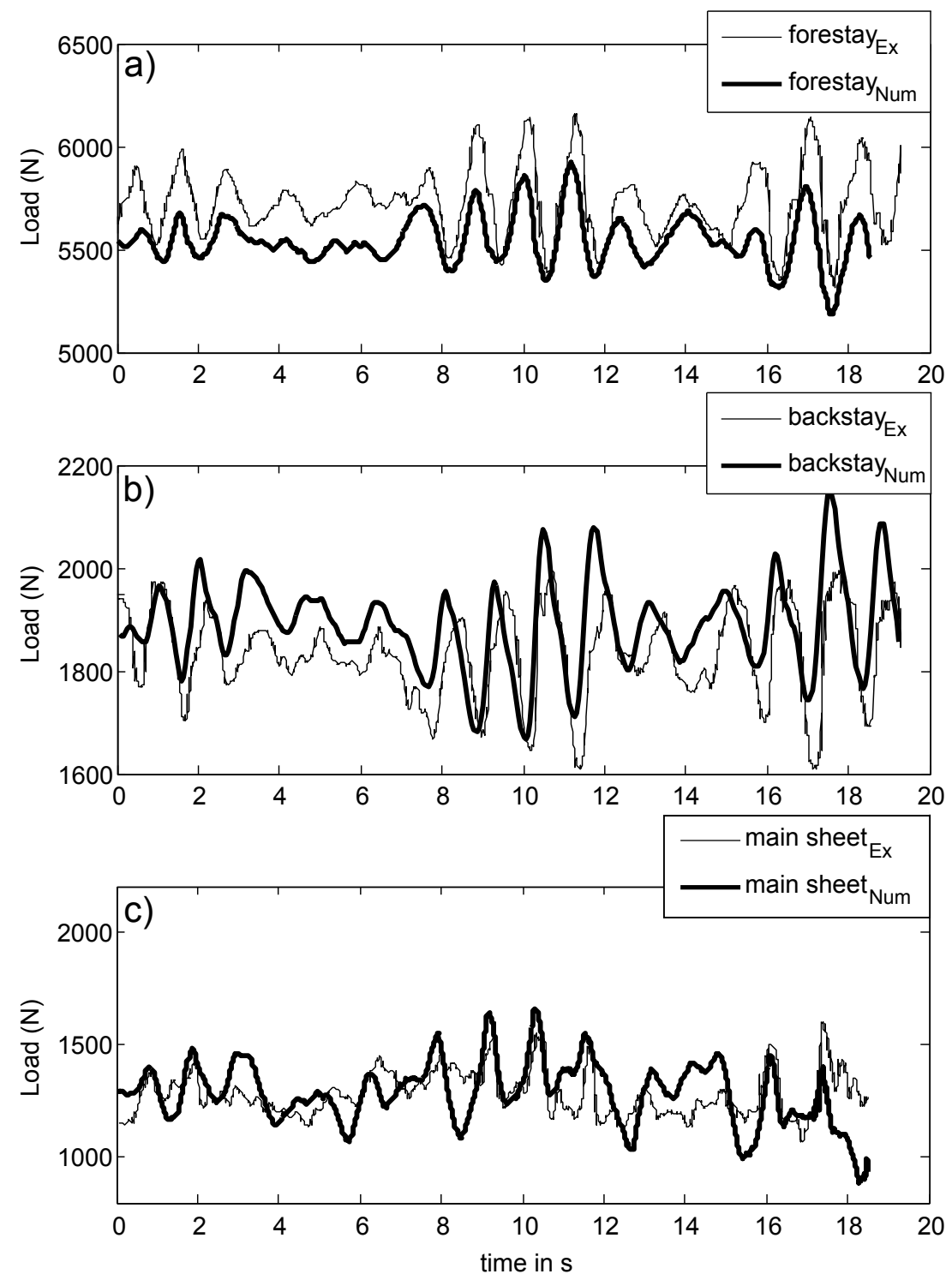

Figure 4: Comparison of load variations in forestay (a), backstay (b) and main sheet (c) due to pitch forcing between the measured (Ex-thin line) and calculated (Num-bold line) signals. 


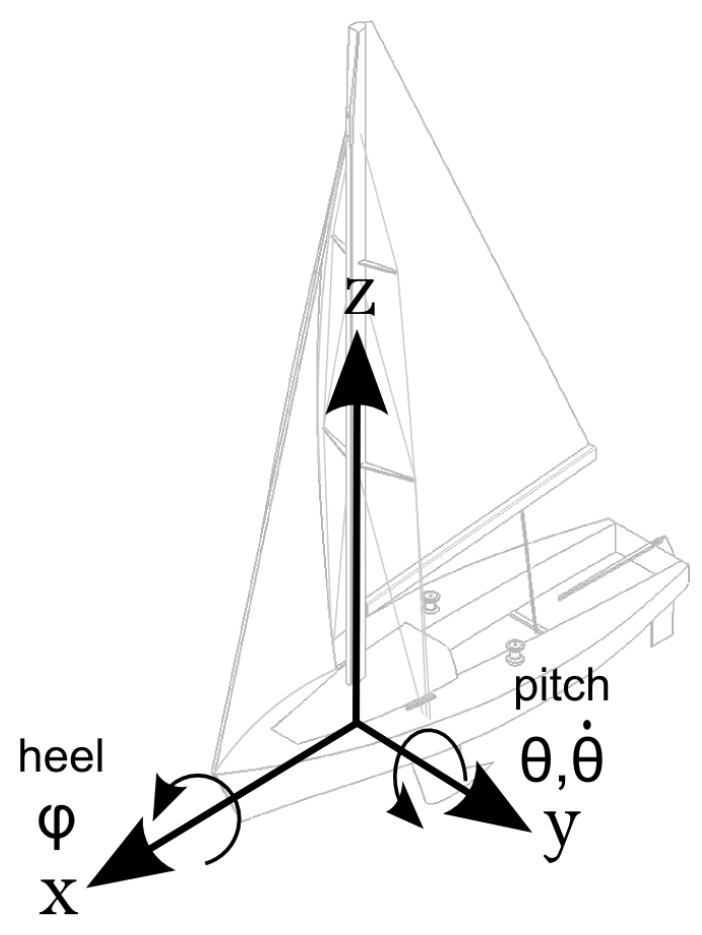

Figure 5: Coordinate, angle and motion references for the yacht 


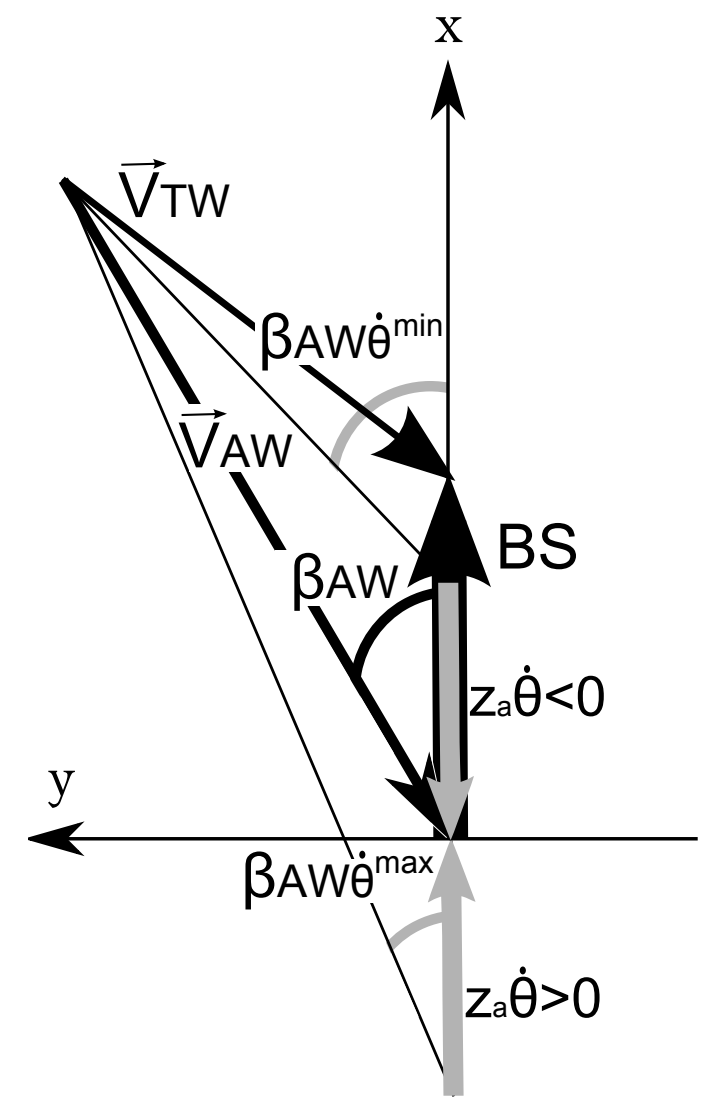

Figure 6: Dynamic effect of pitching on the wind triangle (top view). $\vec{V}$ is the wind velocity, BS is the boat speed, $\mathrm{z}$ is the height of the aerodynamic centre of effort, $\dot{\theta}$ is the pitching velocity, $\beta$ is the apparent wind angle, subscripts TW and AW stand for True and Apparent wind 

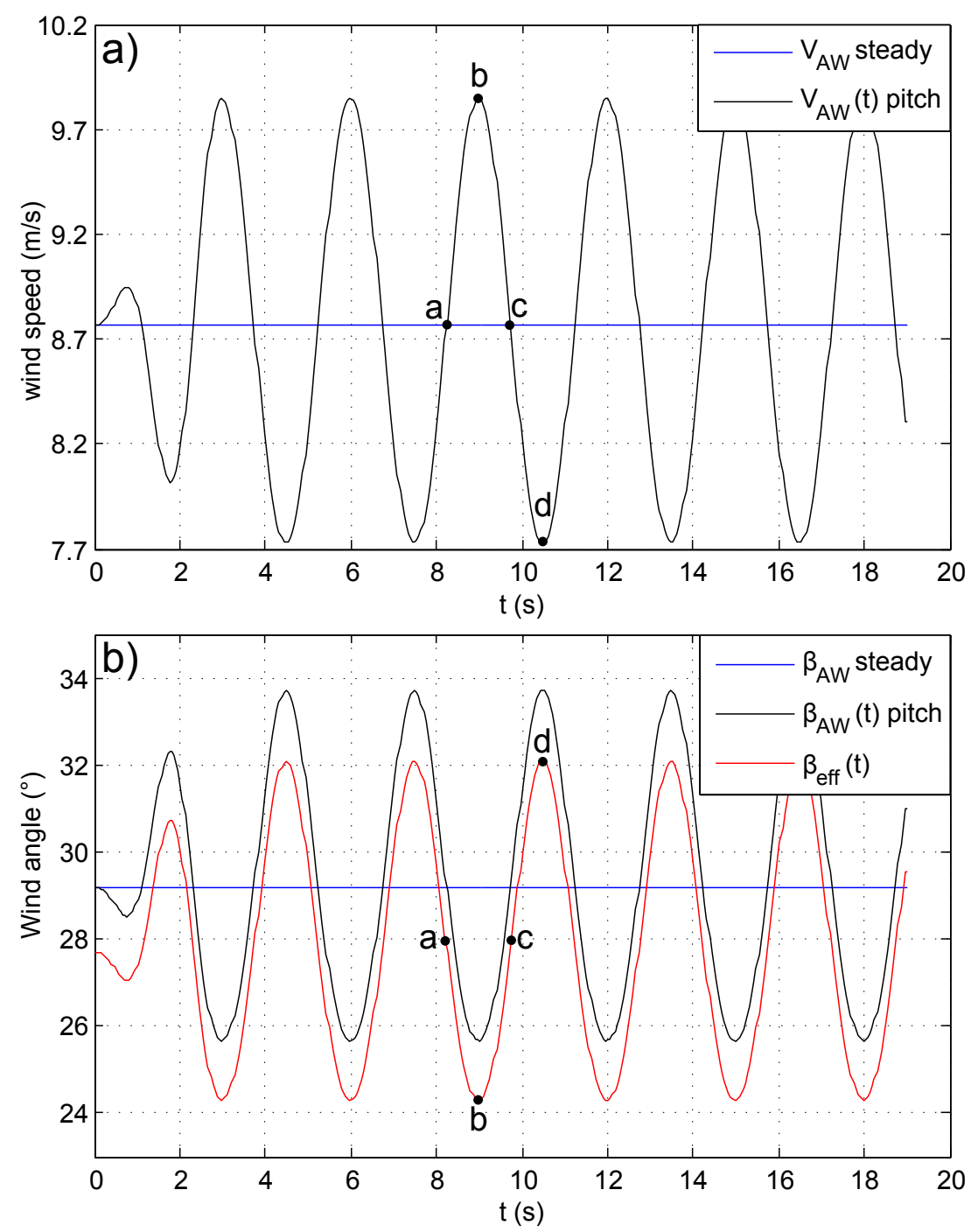

Figure 7: Time dependent apparent wind speed $\mathrm{V}_{A W}$ (a) ; apparent wind angle $\beta_{A W}$ and effective wind angle $\beta_{\text {eff }}$ (b) resulting from pitching oscillation with period $\mathrm{T}=3 \mathrm{~s}$ and amplitude $\mathrm{A}=5^{\circ}$. Letters on the signals refer to the snapshots of figure 8 


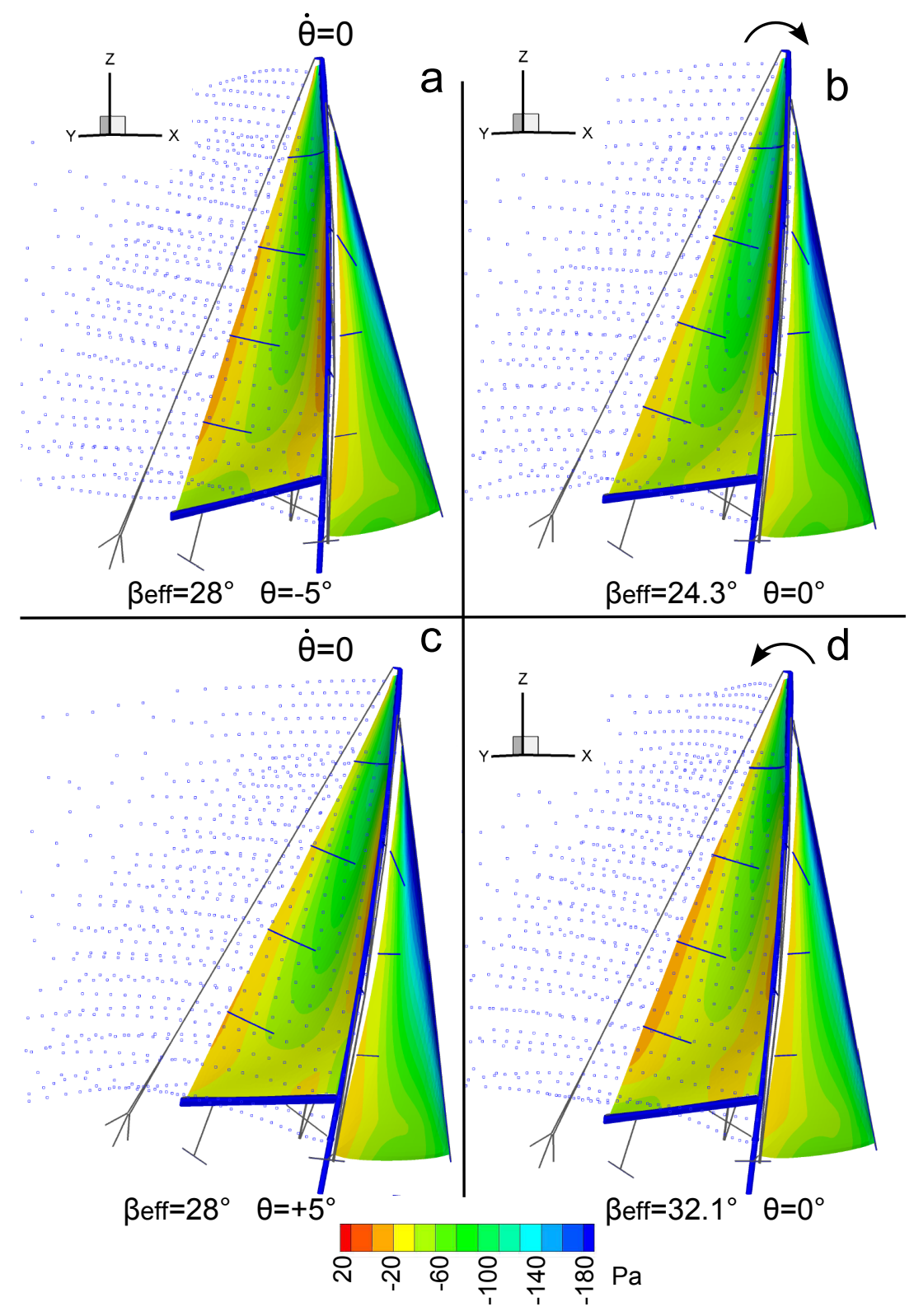

Figure 8: Pressure jump distribution and wake due to a pitching oscillation with $5^{\circ}$ amplitude and 3 s period. The time of each snapshot is indicated on Figure 7. Arrows represent the pitching direction. $\theta$ is the trim angle, $\dot{\theta}$ is the pitching velocity, $\beta_{\text {eff }}$ is the effective wind angle. 

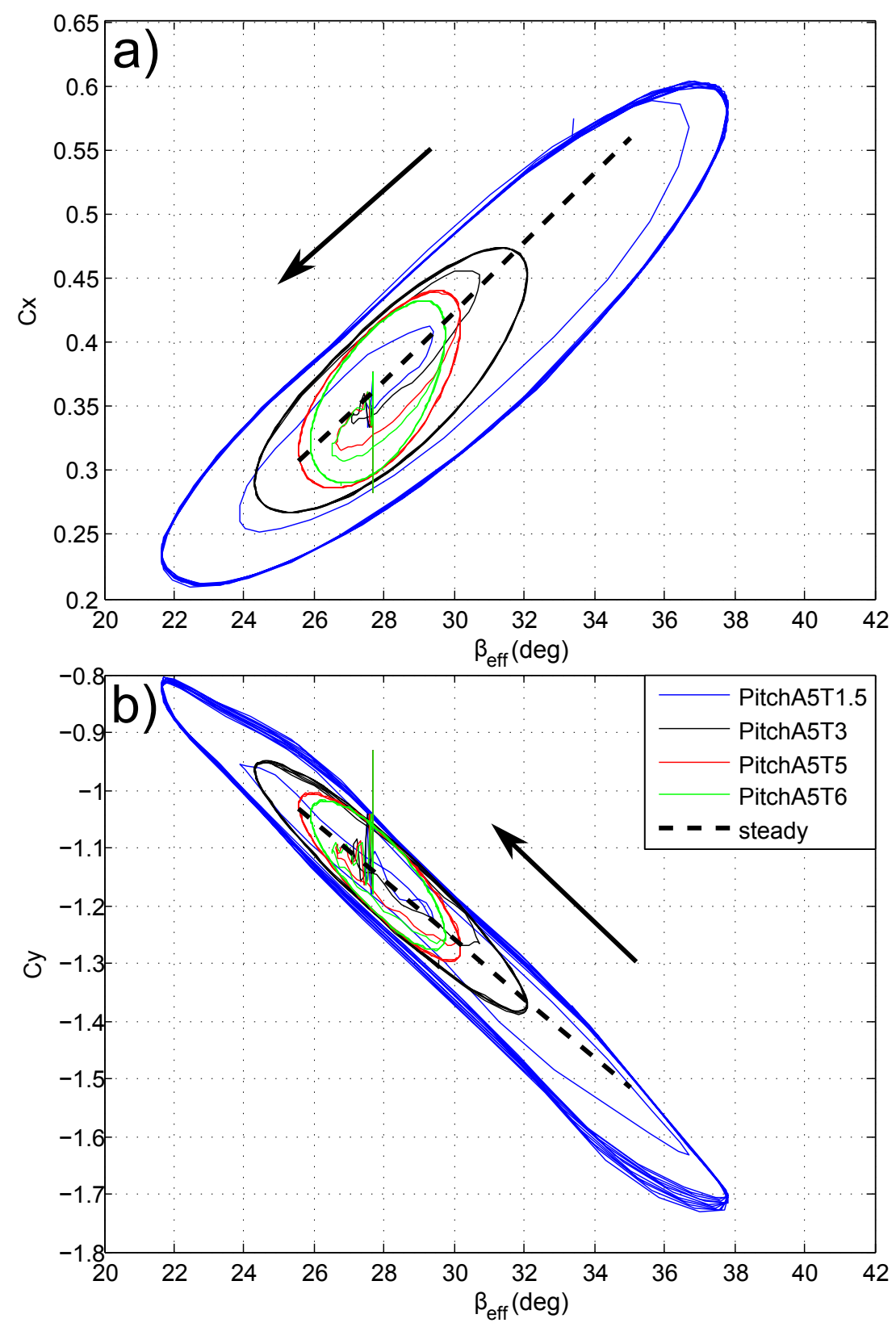

Figure 9: Driving (a) and heeling (b) force coefficients vs. the effective wind angle $\beta_{\text {eff }}(\mathrm{t}$ ) at different pitching periods $\mathrm{T}=1.5,3,5$ and $6 \mathrm{~s}$ with a $5^{\circ}$ amplitude. The rotation direction is shown by the arrows. The steady state variation with $\beta_{\text {eff }}(\mathrm{t})$ is also shown (dashed line). 

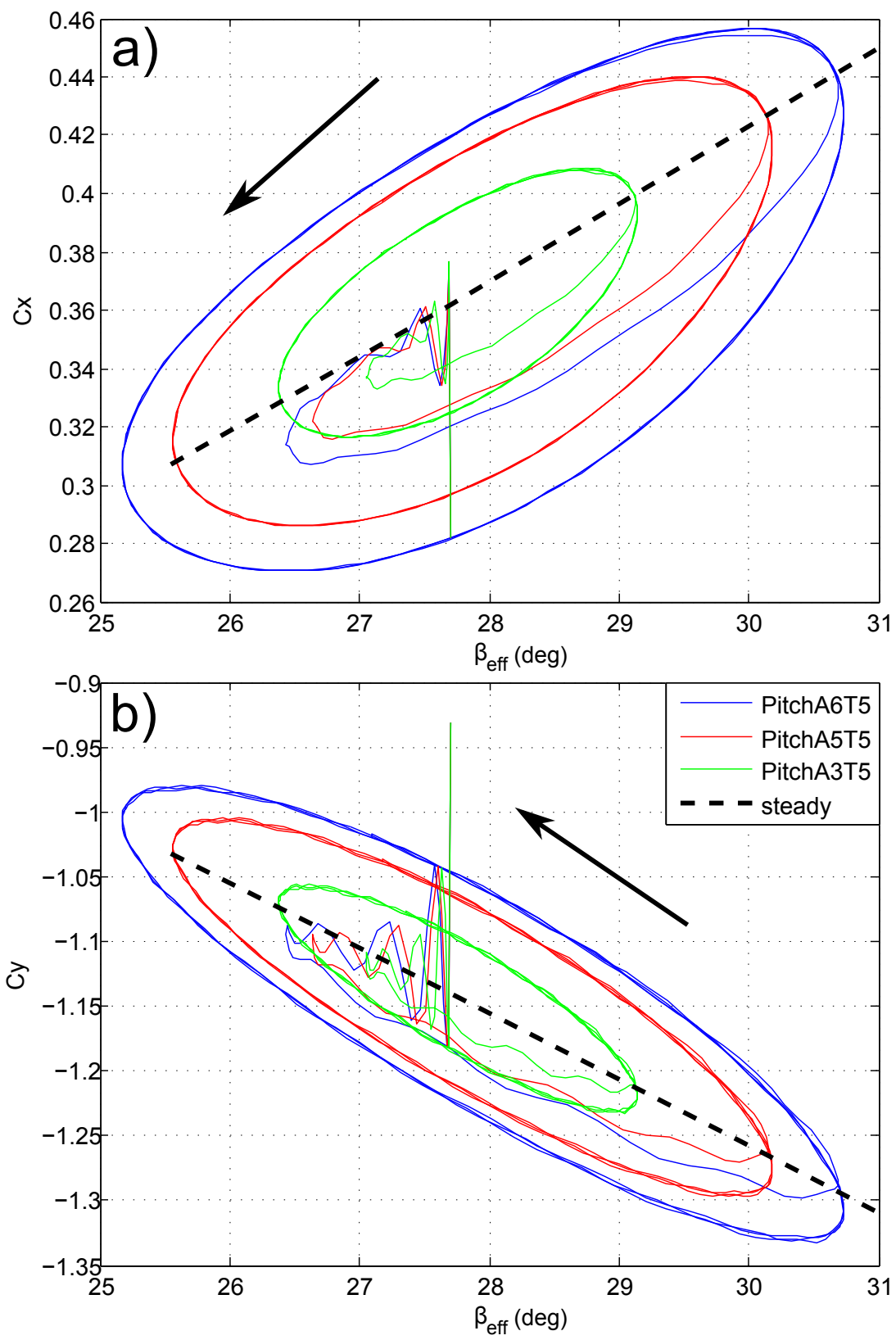

Figure 10: Driving (a) and heeling (b) force coefficients vs. the effective wind angle $\beta_{\text {eff }}(\mathrm{t})$ at different pitching amplitudes $\mathrm{A}=3,5$ and $6^{\circ}$ with a $5 \mathrm{~s}$ period $\mathrm{T}$. The rotation direction is shown by the arrows. The steady state variation with $\beta_{\text {eff }}(\mathrm{t})$ is also shown (dashed line). 

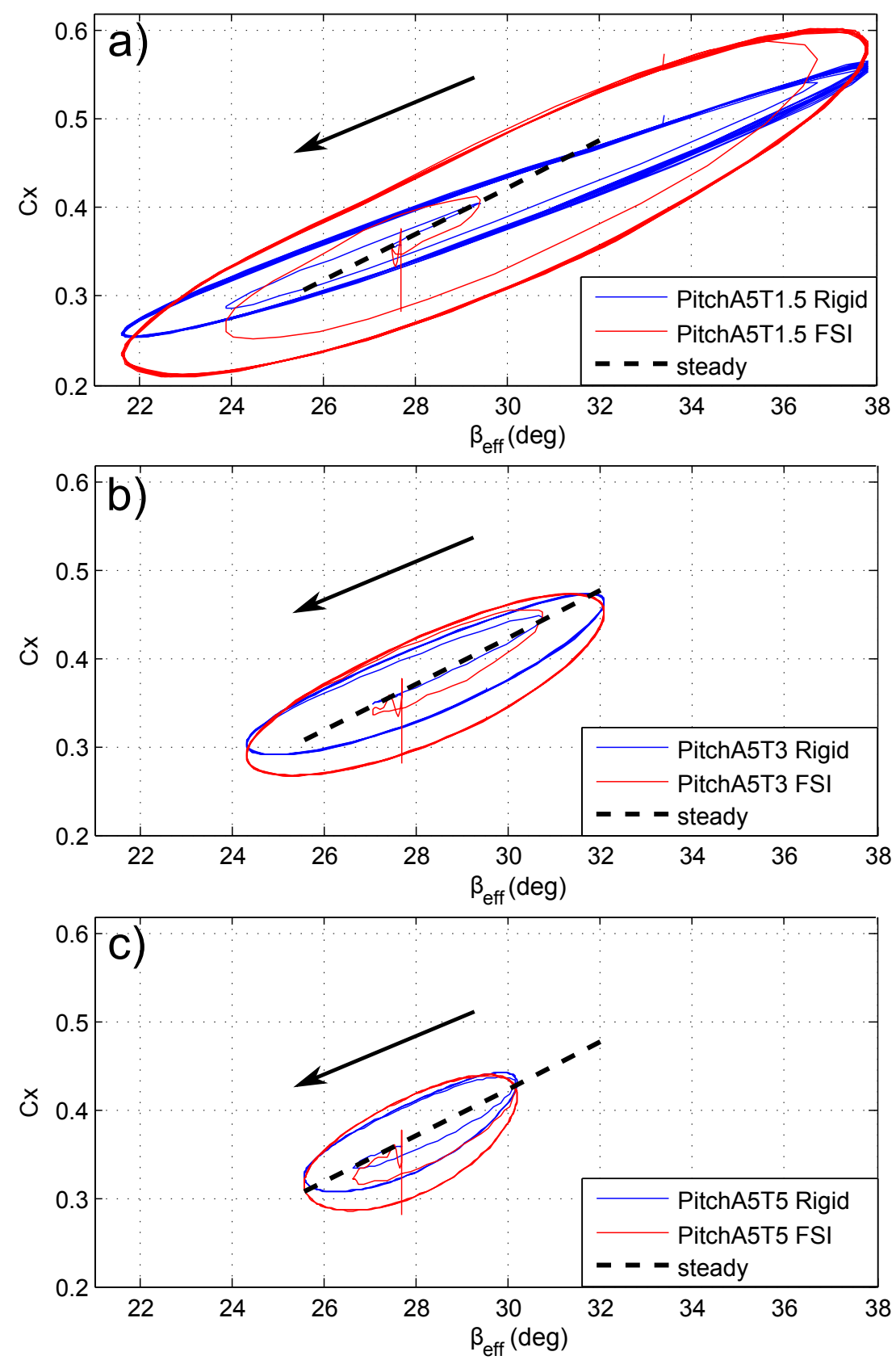

Figure 11: Comparison of force coefficients for rigid (blue line) and flexible (red line) structures: driving force coefficient vs. the effective wind angle $\beta_{\text {eff }}(\mathrm{t})$ at different pitching periods $\mathrm{T}=1.5 \mathrm{~s}(\mathrm{a}), \mathrm{T}=3 \mathrm{~s}(\mathrm{~b})$ and $\mathrm{T}=5 \mathrm{~s}(\mathrm{c})$ at $5^{\circ}$ amplitude. The steady state variation with $\beta_{\text {eff }}(\mathrm{t})$ is also shown (dashed line). $\quad 39$ 

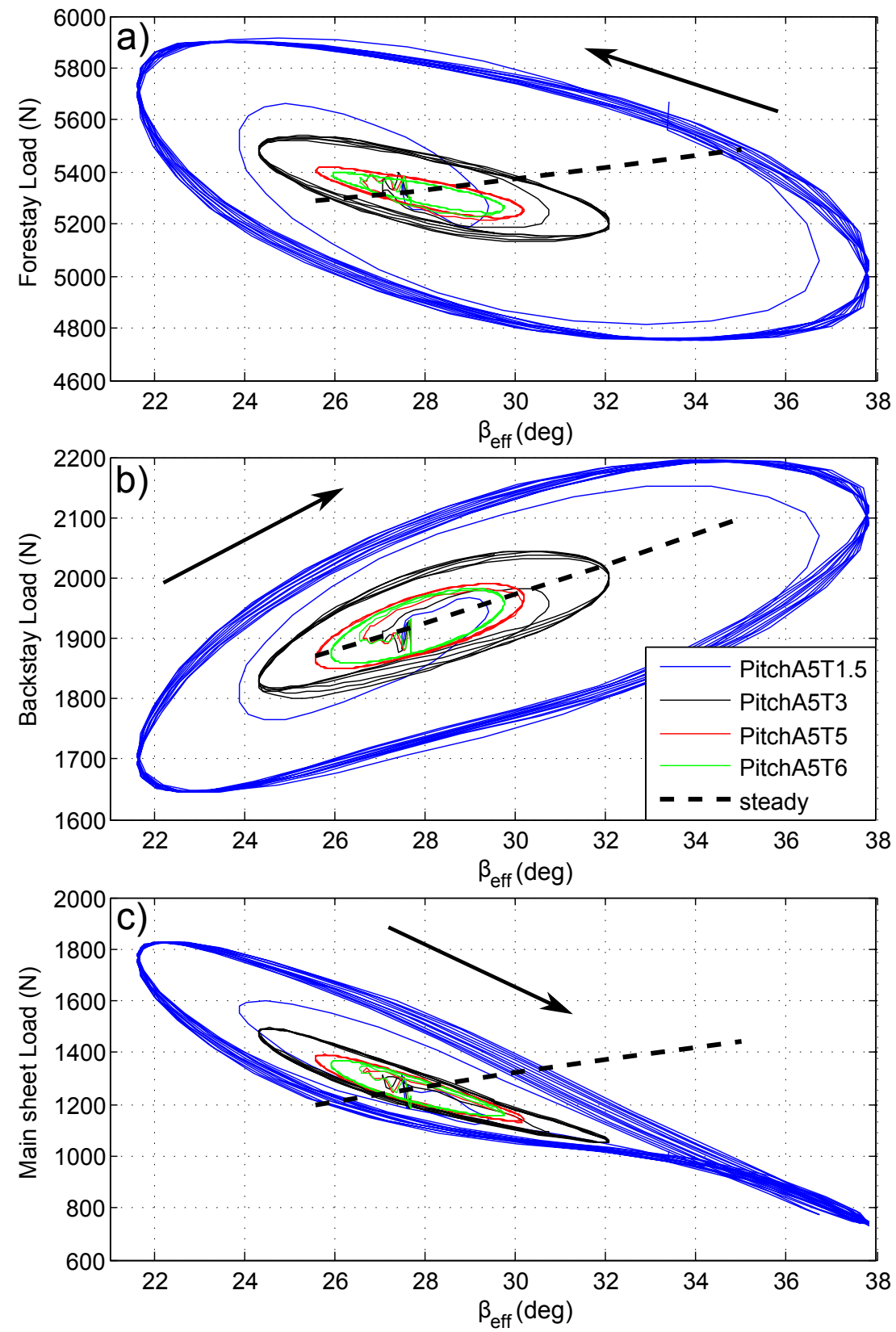

Figure 12: Loads in rigging, forestay (a), backstay (b) and main sheet (c), vs. the effective wind angle $\beta_{\text {eff }}(\mathrm{t})$ at different pitching periods $\mathrm{T}=1.5,3,5$ and $6 \mathrm{~s}$ with a $5^{\circ}$ amplitude A. The steady state variation with $\beta_{\text {eff }}(\mathrm{t})$ is also shown (dashed line). 

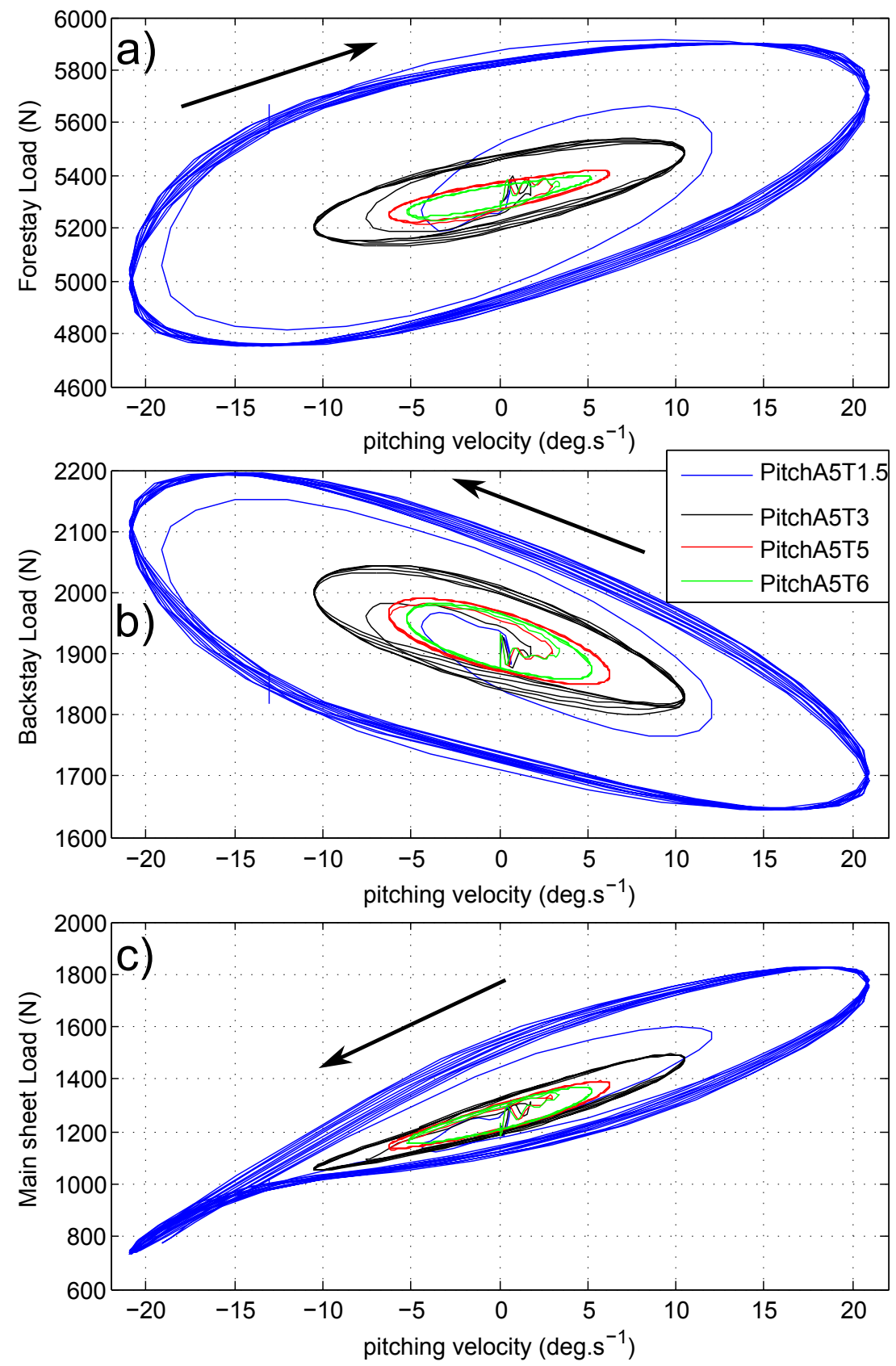

Figure 13: Loads in rigging, forestay (a), backstay (b) and main sheet (c), vs. pitching velocity $\dot{\theta}(\mathrm{t})$ at different pitching periods $\mathrm{T}=1.5,3,5$ and $6 \mathrm{~s}$ with a $5^{\circ}$ amplitude A. 

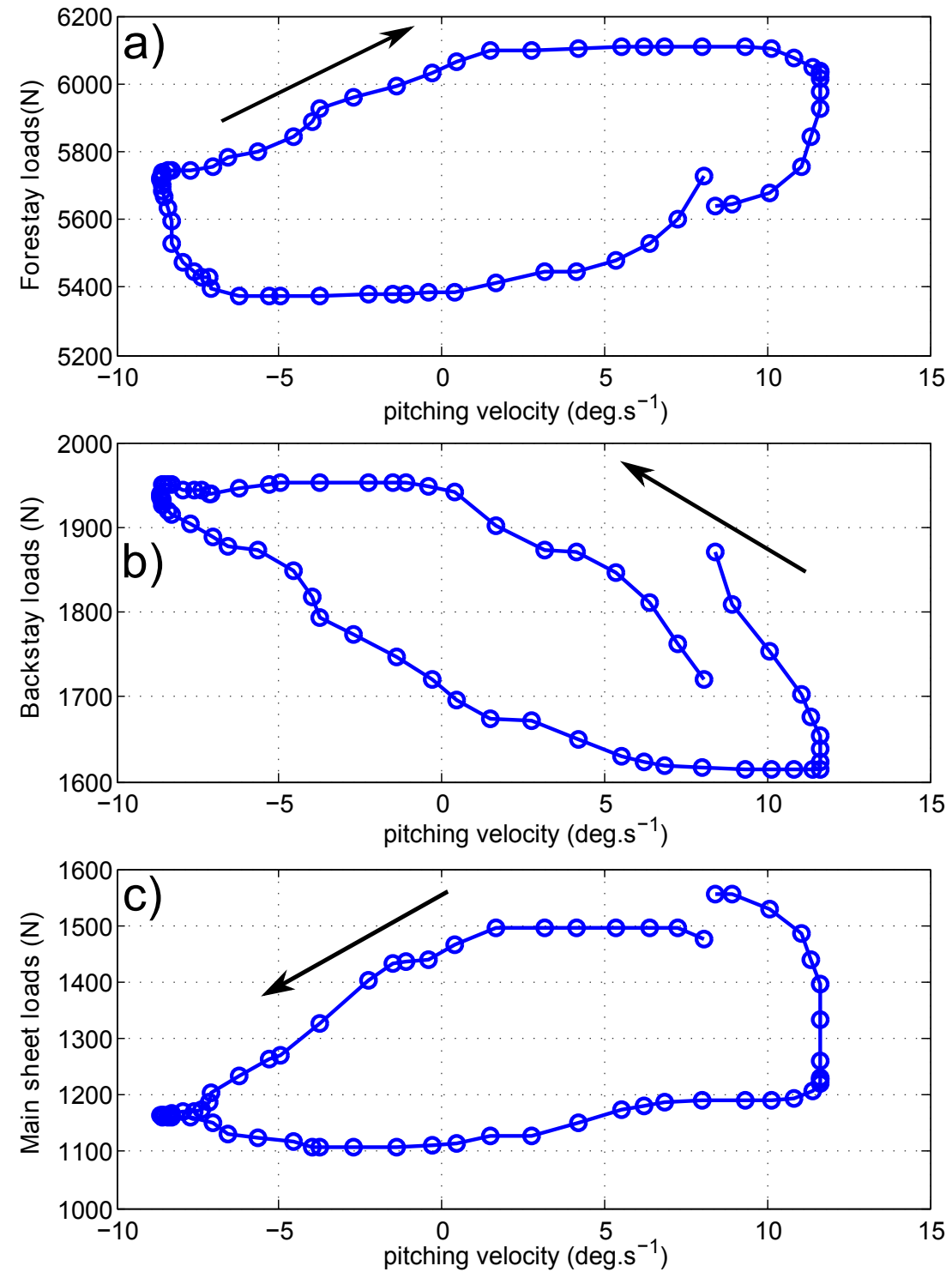

Figure 14: Experimental loads in rigging, forestay (a), backstay (b) and main sheet (c), vs. pitching velocity $\dot{\theta}(\mathrm{t})$ for a $1.3 \mathrm{~s}$ period head swell. Blue markers represent the load measured on the instrumented boat for a single period. 